\title{
O lugar da cultura e da identidade na formação do professor de língua ${ }^{1}$
}

\author{
El lugar de la cultura y la identidad en la formación de profesores de \\ idiomas
}

The place of culture and identity in language teacher training

\author{
Nelson de Jesus Teixeira Júnior² \\ Maria Elia dos Santos Teixeira de Carvalho ${ }^{3}$
}

\begin{abstract}
Resumo
O presente artigo visa discutir a experiência do estudante de Letras enquanto momento de constituição das identidades e das percepções culturais por meio da língua. Esse momento de experimentação da constituição identitária do cursista de Letras, o qual ocupa um entre-lugar de vivência em condições fronteiriças entre aquele que estuda e aquele que ensina, ocorre durante o uso e a reflexão em torno da língua. Nessa condição de constituição das identidades, discutiremos sobre como ocorre essa experiência, dando destaque ao componente curricular de Estágio e suas especificidades. Como fundamentação teórica usada durante as problematizações apontadas e refletidas, recorremos a algumas postulações de Bakhtin (2013), de Hall (2005), de Bhabha (2003), da BNCC (2018) dentre outros pensadores e/ou documentos oficiais.
\end{abstract}

Palavras-Chave: Língua; Identidade; Cultura; Letras.

\section{Resumen}

Este artículo tiene como objetivo discutir la experiencia del estudiante de Letras como un rato de constitución de identidades y percepciones culturales por medio del lenguaje. Este rato de experimentación de la constitución de identidad del estudiante de Letras, que ocupa un lugar intermedio de vivir en condiciones fronterizas entre el que estudia y el que enseña, ocurre durante el uso y la reflexión en torno al idioma. En esta condición de constitución de identidades, discutiremos cómo ocurre esta experiencia, destacando el componente curricular de pasantía y sus especificidades. Como base teórica utilizada durante las problematizaciones

\footnotetext{
1 Artigo apresentado no II Congresso Internacional Online de Estudos sobre Culturas, na modalidade online, 2020 .

${ }^{2}$ Doutor em Letras pela Universidade Estadual Paulista - UNESP, campus de São José do Rio Preto - SP. Professor de "Estágio em Letras" na Universidade do Estado da Bahia - UNEB, campus de Barreiras - BA. njtjunior@uneb.br

${ }^{3}$ Mestra em Educação pela Universidade Estadual de Santa Cruz - UESC/Ba. Doutoranda em Letras: Linguagens e Representações - UESC. Professora de Língua Espanhola no Instituto Federal Baiano - IFBAINO, campus Uruçuca-Ba. mariaelia.carvalho@yahoo.com.br
} 
señaladas y reflejadas, recurrimos a algunas postulaciones de Bakhtin (2013), Hall (2005), Bhabha (2003), BNCC (2018) entre otros pensadores y / o documentos oficiales.

Palabras claves: lenguaje; Identidad; Cultura; Letras.

\begin{abstract}
This article aims to discuss the experience of the student of Literature as a moment of constitution of identities and cultural perceptions through language. This moment of experimentation of the identity constitution of the Letters student, which occupies an interplace of living in border conditions between the one who studies and the one who teaches, occurs during the use and reflection around the language. In this condition of constitution of identities, we will discuss how this experience occurs, highlighting the internship curricular component and its specificities. As a theoretical basis used during the problematizations pointed out and reflected, we resort to some postulations of Bakhtin (2013), Hall (205), Bhabha (2003), BNCC (2018) among other thinkers and / or official documents.
\end{abstract}

Keywords: Language; Identity; Culture; Letters.

\title{
1. CONSIDERAÇÕES INICIAIS
}

A língua é um fenômeno social que para além da representação do território geográfico, da história do seu povo e da condição linguística dos seus falantes, traz, ainda, a qualidade perene de manifestar ininterruptamente a cultura e as identidades do seu usuário. Essa perenidade ultrapassa a condição do som, do sentido e da imagem das palavras, ecoando, inclusive, na forma como o usuário da língua, especialmente o estudante do curso de Letras, que ao selecionar os materiais para a aula, afeta e se afeta com as culturas e as identidades em tela.

Em razão desse processo de acesso, de organização e de socialização da língua como recurso de trabalho (durante o estágio), propomos discutir aspectos que podem escapar a esse instante tão importante, que é a entrada do aluno de Letras no espaço de aula, ainda que na condição de estagiário. Como recursos metodológicos, refletiremos sobre críticos, teóricos e documentos oficiais que versam sobre a língua, a cultura e a identidade.

Portanto, o cenário enriquecedor de uma aula, pensado ainda na sua etapa inicial, pode ser significativo ao interessado pela compreensão do quanto a língua pode contribuir na compreensão de SI e do OUTRO, pois a escola é, também, "[...] o lugar de uma atividade coletiva de produção de sentido". (KERBRAT-ORECCHIONI, 1990, p. 28). Neste sentido, questionamos o processo de constituição das identidades e das culturas no sujeito/estagiário 
que, por sua vez, se encontra no processo de ser estudante/professor. Nosso intuito não é apresentarmos respostas, mas apontar caminhos que possibilitem trazer para o debate possibilidades de reflexões sobre o tornar-se professor no período de estágio.

\section{LÍNGUA, CULTURAS E IDENTIDADES ENQUANTO ASPECTOS DO CURSO DE LETRAS}

No decorrer do curso de Letras o/a acadêmico/a apresentará conhecimentos prévios sobre a Linguagem e na medida que as discussões, leituras, desconstruções vão sendo trazidas para o debate, essa compreensão vai se ampliando tomando, assim, novas proporções. A concepção de linguagem que defendemos aqui está ancorada no círculo bakhtiniano, o qual entende a linguagem como processo discursivo decorrente das interações sociais. Dentro da compreensão bakhtiniana a língua(gem) é uma atividade social e como tal dá-se na interação entre o locutor e o interlocutor através de enunciações. Afinal,

[...] toda palavra comporta duas faces. Ela é determinada tanto pelo fato de que procede de alguém, como pelo fato de que se dirige para alguém. Ela constitui justamente o produto da interação do locutor e do ouvinte. Toda palavra serve de expressão a um em relação ao outro. Através da palavra defino-me em relação ao outro, isto é, em última análise, em relação à coletividade." (BAKHTIN/VOLOCHINOV, 2006, p. 117, grifos dos autores).

Nessa perspectiva de linguagem enquanto processo, Bakhtin defende que todas as esferas da atividade humana se dão através dos gêneros do discurso, que por sua vez podem ser primários (os gêneros do cotidiano, informais, espontâneo) e os secundários (gêneros mais elaborados, formais, mais complexos). Ao fazer usos rotineiramente desses gêneros, o sujeito se constitui na/pela linguagem através do discurso, que por sua vez é marcado pela heterogeneidade de "diversas vozes", advindas de outros espaços /discursos.

Neste momento queremos nos ater a estas vozes que ressoam ao do cursista de Letras nos espaços que lhes são apresentados através do estágio. É preciso considerar ainda que ao partir para o estágio começa a entrar em cena um "novo eu", o "eu" professor, mesmo que por curto espaço de tempo. Esse novo "eu" é também atravessado por outras linguagens, identidades e culturas que serão evocadas em um outro espaço de vivência, a sala de aula.

O universo escolar, em sua dinâmica de funcionamento, representa um espaço multifacetado no qual há um convívio social cujo tempo está dividido por turnos, o que não compromete a proporção das relações ali estabelecidas. O movimento cotidiano da escola, 
geralmente, é composto por trabalhadores que em menor ou maior proporção contribuem na formação dos sujeitos que compõe esse cenário social que vai desde professores, estudantes, coordenadores, diretor/a, cozinheiros/as, secretários/as dentre outros. É justamente neste espaço que o sujeito estagiário vai passar um tempo suficiente para também ser voz e ser interpelado por outras vozes.

Vale lembrar que, para além do momento de passagem, o período de estágio envolve um contexto de identificação com a área de atuação, pondo em questão as formas de socialização do saber, a aquisição de novas ideias crítico-teóricas e, ainda, a reformulação de antigas certezas sobre a língua portuguesa, no caso do estudante de Letras. Nesse sentido, conforme Nóvoa (2013), a construção da identidade docente é um processo em que o envolvido se impacta com tais acréscimos, já que “[...] se apropria do sentido da sua história pessoal e profissional". (NÓVOA, 2013, p. 16).

Todo esse cenário, que envolve aspectos pessoais e profissionais, constrói o ambiente propício para a constituição das identidades, ainda que em circunstância de fragmentação. Conforme discutimos, tentaremos, no presente texto, captar particularidades que estão inseridas nessa constituição identitária e cultural que adentra no processo de configuração do "EU" no espaço de Estágio em Letras. É preciso pontuar que a língua possibilita ao seu usuário estados de identificação com sua cultura e, nesse processo de identificação, as identidades são constituídas. Esse momento de constituição sobre "si", conforme pontua Bhabha (2003), ocorre na fronteira estabelecida pela cultura: "O trabalho fronteiriço da cultura exige um encontro com 'o novo' que não era parte do continuum de passado e presente". (BHABHA, 2003, p. 27). Para além da expressão da forma, do som e do pensamento, a linguagem ocupa um locus de enunciação dos sujeitos, o comunicar-se com outro carrega representações de si e das vozes que o atravessam em suas práticas discursivas.

É preciso pontuar que esse estado de "flutuação" da identidade acompanhará o estudante de Letras durante toda a sua experiência acadêmica e docente, especialmente em função dos espaços de aula ocupados por esse sujeito nas letras. Conforme todos sabem, o período do estágio é aquele momento em que o estudante organiza a execução daquilo que, até então, apontava à própria formação. Nesse deslocamento do "EU" para o "OUTRO", há uma reconfiguração daquilo que sou em função do que serei. Agora, novas cisões acontecerão sobre as identidades do estudante de Letras, isso pela via do contato com impressos, audiovisuais, textos e outros recursos que podem possibilitar o acesso dos alunos durante a regência do estágio. 
Durante o curso de Letras, o estudante recebe contribuições, teóricas e críticas, quanto à sua formação enquanto cursista. Durante o estágio, esse fluxo amplia a direção, sendo alvo, além do próprio estudante de letras, o aluno do ensino básico, que receberá o estagiário em seu espaço de aula. Nesses dois momentos, através da linguagem, esses sujeitos terão acesso às várias culturas presentes na escola, além das identidades advindas do "outro", quer seja do professor, alunos, enfim, de toda a comunidade escolar. Toda essa relação multicultural vivenciada pelo estagiário tomará um novo significado na sala de aula. A esse respeito, Roldão (2007) traz a seguinte contribuição para essa discussão:

A formalização do conhecimento profissional ligado ao ato de ensinar implica a consideração de uma constelação de saberes de vários tipos, passíveis de diversas formalizações teóricas - científicas, científico didáticas, pedagógicas (o que ensinar, como ensinar, a quem e de acordo com que finalidades, condições e recursos), que contudo, se jogam num único saber integrador, situado e contextual - como ensinar aqui e agora -, que se configura como 'prático'. (ROLDÃO, 2007, p. 98).

O contato com a língua que se traduz em novos discursos traz esse impacto para o falante: a formação ininterrupta de identidades, mesmo que, por vezes, pelo caminho da intertextualidade. Essa intertextualidade entendemos como o cruzamento de vozes pela via da oralidade, pela via do impresso, pela via das imagens, enfim, pela via das linguagens e suas representações.

A língua provoca/evoca a comunicação como ato de manifestação do presente e, ao mesmo tempo, retoma o passado de outras tantas manifestações. Esse caráter histórico é o que chamamos de aspecto coletivo e que, somado ao presente do falante, contribui para o dinamismo discursivo. Todo esse entre - lugar, presente na língua, funciona como agregador de sentidos culturais e identitários aos sujeitos do discurso. Velloso (2000) assegura que ao pensar o nosso país, aqui adicionamos a língua como recurso de reflexão, pensamos sobre nós mesmos. Por isso a importância de entender aspectos culturais e identitários presentes na língua.

Por outro lado, o que nos aproxima desse estado de fragmentação identitária é reconhecer que - superando a dicotomia teoria x prática, tão comum na rotina do estudante de licenciatura - o Estágio aparece como um componente curricular que reforça o processo de mesmidade e alteridade do discente do curso de Letras. Sobre essa condição de fluidez da identidade, 
Em toda parte, estão emergindo identidades culturais que não são fixas, mas que estão suspensas, em transição, entre diferentes posições; que retiram seus recursos, ao mesmo tempo, de diferentes tradições culturais. (HALL, 2005, p. 88).

Segundo Hall, essas aparições de identidades acontecem com aspectos de transitoriedade. Essa contradição entre não ser mais o mesmo e, ao mesmo tempo, estar em circunstância de alguém em passagem é, durante o Estágio, muito importante para o estudante de Letras, especialmente no que tange ao processo de identificação para o qual o componente curricular em discussão pode contribuir de forma efetiva.

O componente curricular de Estágio Supervisionado em Letras produz, quando bem planejado, bem executado e com vistas ao elo entre teoria e prática, condições propícias à constituição de identidade ao estudante de Letras; principalmente quando, durante a tessitura do planejamento da disciplina, ele reproduz - guardadas as devidas proporções - a cultura escolar que encontrará no ambiente de ensino.

A Base Nacional Comum Curricular (2018), ao tratar da qualificação das intervenções por meio das práticas na área das Linguagens e suas Tecnologias, assegura que:

Para isso, é fundamental que sejam garantidas aos estudantes oportunidades de experimentar fazeres cada vez mais próximos das práticas da vida acadêmica, profissional, pública, cultural e pessoal e situações que demandem a articulação de conhecimentos, o planejamento de ações, a auto-organização e a negociação em relação a metas. (BRASIL, 2018, p. 478).

A Base Nacional Comum Curricular (BNCC), ao apontar para esse caráter formativo voltado ao aluno do ensino básico, conclui com a sugestão de metas para a formação do estudante na graduação, pois esta precisa ter competências e habilidades para conduzir os alunos no espaço de aula. Nesse processo de antecipação ao que será comum no espaço público, como, por exemplo, na escola, o estudante de Letras lançará mão do seu repertório crítico, teórico e sociocultural de ensino, além dos conhecimentos que propiciam a constituição de suas fluidas identidades.

A participação do estudante de Letras no ato da seleção de textos, da compreensão e da construção de sentidos sobre a manifestação da linguagem nesses materiais impressos levao, sem dúvidas, a um processo de identificação com as manifestações culturais ali instaladas. Nesse momento, ao preparar sua aula com vistas na intertextualidade, as identidades e as culturas entram em jogo.

Para inserir o estudante do ensino básico, público alvo do estudante de Letras, nas condições de representatividade do cotidiano, o cursista de Letras precisa, antes de tudo, 
operacionalizar/dialogar os conceitos, bem como, promover reflexões sobre as teorias e práticas que lhes foram apresentados durante o curso de Letras e, nesse sentido, a leitura deverá ter sido uma constante em sua formação. A BNCC (2018) narra o seguinte cenário para os alunos do Ensino Médio:

Ao chegar ao Ensino Médio, os estudantes já têm condições de participar de forma significativa de diversas práticas sociais que envolvem a linguagem, pois, além de dominarem certos gêneros textuais / discursivos que circulam nos diferentes campos de atuação social considerados no Ensino Fundamental, eles desenvolveram várias habilidades relativas aos usos das linguagens. (BRASIL, 2018, p. 490).

Para o documento acima, os gêneros textuais/discursivos devem ter um lugar relevante no espaço escolar, visto que a BNCC entende os gêneros enquanto atividades humanas que são produzidos nas linguagens quer sejam orais ou escritos. Infelizmente, a nosso ver, o trabalho com os gêneros discursivos na sala de aula ainda acontece de maneira tímida ou equivocada. Nesta perspectiva de entendimento, Coscarelli (2007) chama a atenção para o tratamento tímido e inflexível dado aos gêneros no espaço escolar, condição que deve ser revista.

Inquestionavelmente, o período de estágio é tão simbólico que apresenta condições da constituição do "EU" e do "OUTRO" nas relações entre o estudante de Letras e o aluno do Ensino Médio. É um momento propício para, no processo de constituição das identidades, desconstruírem-se obstáculos que impeçam a constituição de todos, pois

A escola de Ensino Médio deve desenvolver ações para que todos (as), negros (as) e não-negros (as), construam suas identidades individuais e coletivas, garantindo o direito de aprender e de ampliar seus conhecimentos, sem serem obrigados a negar a si próprios ou ao grupo étnico-racial a quem pertencem. (SOUZA, 2006, p. 89).

Esse enfrentamento às questões que separam as pessoas por meio da indiferença e/ou da perseguição deve ser assumido, no espaço de aula, como um ato de vigilância, pois as formas de exercício do poder da linguagem podem propagar o ódio, a indiferença, a separação, a estereotipia, enfim, atos que representam a redução do outro durante as relações na quais se defrontam o dominante e o dominado. Esse cenário de violência, por vezes simbólica, leva à não aceitação da vítima, condição que limita a constituição das identidades no espaço de aula.

A língua, seja na instância escrita ou oral, propicia ao falante a condição de disfrutar de sua identidade, mesmo que em estágio de descoberta, afinal: 
A identidade é ao mesmo tempo estável e provisória, individual e coletiva, subjetiva e objetiva, biográfica e estrutural, dos diversos processos de socialização que constroem os indivíduos e definem as instituições. (DUBAR, 1991, p.07).

No caso do espaço de aula de estágio, os estudantes de Letras, assim como os do ensino básico durante tal regência, apropriam-se de tais constituições identitárias.

A identidade possibilita não somente a representação de como ser, mas de como atuar. A partir dessa perspectiva, o Estágio incitará o estudante de Letras a assumir-se como resistente ao contexto enfrentado no seu cotidiano. Reichmann (2015) pontua parte desse obstáculo docente ao indicar uma situação pertinente na condução do componente curricular de Estágio na universidade, pois:

De certa forma, nós, professores orientadores da disciplina de estágio, nos vemos engajados em uma tarefa hercúlea, qual seja, a construção de sentidos entre as políticas públicas, o currículo acadêmico, a realidade escolar e o desenvolvimento profissional. (REICHMANN, 2015, p. 24).

Esse instante de contestação e constatação forma o cenário propício para o professor do componente curricular de Estágio estabelecer pontes que possibilitem, aos estudantes de Letras, a compreensão da importância das culturas e das identidades na língua.

Esse processo de ir e vir, de erigir e de ruir, de se aproximar e de se distanciar reconfigura o exercício docente e leva o estudante de Letras à condição de identidades e culturas fluidas. O que parece ser unidirecional é, na verdade, multidirecional; ou seja, ao se constituir enquanto tal, o cursista de Letras processa a ideia de ensino e de aprendizagem, bem como seu lugar na universidade e a importância da disciplina de estágio nesse momento. A partir daqui, talvez não necessariamente "somente a partir daqui", tal estudante equilibre a relação necessária que envolve a todos: professor, aluno e, a saber, a língua. Afinal:

A língua tem ainda uma influência poderosa sobre o pensamento daquele que está falando. O pensamento criativo, original, investigativo, que não se afasta da riqueza e da complexidade da vida, não é capaz de se desenvolver nas formas da linguagem impessoal, uniformizada, não metafórica, abstrata e livresca. (BAKHTIN, 2013, p. 42).

Conforme discutimos anteriormente, a língua, na perspectiva bakhtiniana, por ser social envolve a todos em seu processo de produção e, nesse sentido, pode apresentar-se como uma atividade democrática atenta a todas representações. Esse teor de pertencimento coletivo é intensificado no instante do estágio supervisionado, especialmente pelos momentos de reconfiguração pontuados até aqui. 
Essa suspensão ininterrupta da "completação" da cultura, através das identidades, é reforçada pelo dinamismo da língua, a qual se renova por meio dos seus falantes. Esse fenômeno de atualização faz parte dessa faceta da cultura, posto que “(...) nós somos animais incompletos e inacabados que nos completamos e acabamos através da cultura (...)”. (GEERTZ, 1989, p. 36). Esse estado de complementação constante é, por meio da língua, estabelecido através da maneira como observamos e vivemos os acontecimentos linguísticos processados no cotidiano, inclusive no cotidiano de estágio.

Nesses instantes de reconfiguração das identidades do estudante de Letras, é preciso repensar o exercício docente sob outras perspectivas, tais como Oliveira (2010) pontua:

Contudo, os cursos de licenciatura em letras visam à formação de professores; logo, nesses cursos, abordar uma teoria sem fazer conexão entre ela e a prática docente é condenável, levando muitos estudantes a se perguntarem: "Pra que é que a gente tem que estudar isso? Ninguém merece!” E eles estão certos. (OLIVEIRA, 2010, p. 23).

Aqui há uma realidade pouco discutida em situações curriculares, que diz respeito ao estágio: a teoria e a crítica ficam enclausuradas ao componente curricular e, por vezes, à compreensão pequena dos envolvidos. Nesse momento, as composições identitárias caem no risco de não serem plenamente incitadas.

Logo, a partir dessa incongruência entre "o que aprendo e como aplico", o estudante de Letras passa a problematizar a própria atuação sobre o espaço de aula do ensino básico, visto que tais amarras devem ser desobstruídas ou repensadas na organização das aulas. Nesse contexto, a escola passa a ser pensada durante o planejamento, afinal: na relação professor/aluno, enfrentam-se dois tipos de saber, o saber inacabado do professor de Letras e a relativa aprendizagem do aluno, segundo postula Tragtenberg (2012). Além das amarras que envolvem a aplicabilidade da teoria e da crítica, os estudantes de Letras deverão desobstruir os obstáculos cotidianos do espaço escolar e, nesse esforço de enfrentamento, todos sairão beneficiados.

\section{CONSIDERAÇÕES FINAIS}

Frente ao que foi discutido no decurso desse artigo, reconhecemos que a língua possibilita a condição de "morada" das culturas e das identidades, aspectos que envolvem o usuário, ainda que de maneira não prevista pelo mesmo. Inquestionavelmente, o cursista de Letras, durante o estágio, desenvolve a preocupação voltada ao seu público do ensino básico, 
mas ele (o estudante de Letras) não "escapa" às questões da cultura e das identidades pensadas para seu público. Segundo Paraquett (2000), cultura é “o conjunto de tradições, de estilo de vida, de formas de pensar, sentir e atuar de um povo”. (PARAQUETT, 2000, p. 118). Esses estados apontados são próprios da língua e reforçados em muitas situações comunicativas, como no espaço de aula.

Ainda que, durante o estágio, o cursista de Letras se depare com ações procedimentais na escolha de textos, de autores e de conteúdos já previstos pelo material didático usado no espaço escolar, tais ações ultrapassam a tecnicidade, já que são suficientes para provocar um estado de compreensão sobre os efeitos culturais e identitários. Por isso, o estágio é próprio à formação, ampliação e novas constituições das culturas e das identidades, o que reforça para a importância dessa "iniciação" realizada pelo cursista de Letras.

Por fim, o espaço de estágio em Letras promove, aos sujeitos cursistas, as possibilidades de novos atravessamentos pelos discursos, pelas identidades e pelas culturas. Cremos, ainda, que ao ensinar o componente Língua, quer seja a Portuguesa ou as adicionais, o sujeito cursista encontra diante de si um espaço de confluências que é o seu próprio lugar da profissão. Sua Linguagem/identidade/cultura carrega, agora, a voz do outro, a voz da ansiedade por novos saberes, a voz da dor das histórias ouvidas... e, possivelmente, é no estágio que nos deparamos com o privilégio de escutar essas vozes tão silenciadas por políticas de exclusão.

\section{Referências}

BAKTHIN/VOLOCHINOV. Marxismo e Filosofia da linguagem. Tradução de Michel Lahud e Yara Frateschi- 12 ${ }^{\text {a }}$ ed. São Paulo: Hucitec, 2006.

BAKHTIN, Mikhail. Questões de estilística no ensino da língua. In: Questões de estilística no ensino da língua. Tradução, posfácio e notas de Sheila Grillo e Ekaterina Vólkova Américo. São Paulo: Editora 34, 2013.

BHABHA, H. O Local da Cultura. Trad. de Myriam Avila, Eliana Lourenço de Lima Reis, Glaucia Renate Gonçalves. Belo Horizonte: ed. UFMG, 2003.

BRASIL. Base Nacional Comum Curricular: Ensino Médio. Brasília: MEC/Secretaria de Educação Básica, 2018.

COSCARELLI, Carla Viana. A produção de gêneros textuais. Veredas online - Ensino - n. 2, 2007, p. 78-86. Disponível em: www.ufjf.br/revistaveredas/files/2009/12/artigo051.pdf . Acesso em: 17 maio. 2020. 
DUBAR, C. La socialisation. Construction dês indentités sociales ET professionnelles. Paris: Armand Colin, 1991.

GEERTZ, Clifford. A interpretação das culturas. Rio de Janeiro: LTC, 1989.

HALL, Stuart. A identidade cultural na pós-modernidade. Trad. Tomaz Tadeu da Silva e Guacira Lopes Louro 10ª Ed. Rio de Janeiro: DP e A, 2005.

KERBRAT-ORECCHIONI, Catherine. Les interactions verbales. Paris: A.Colin, 1990.

NÓVOA, António. Os professores e as histórias de vida. In: Vidas de professores. 2. ed. Porto: Porto Editora, 2013.

OLIVEIRA, Luciano Amaral. 5 coisas que todo professor de português precisa saber. In: . Coisas que todo professor de português precisa saber: a teoria na prática. São Paulo: Parábola Editorial, 2010.

PARAQUETT, Márcia. Da abordagem estruturalista à comunicativa. In.: TROUCHE e REIS (org.). Hispanismo. Brasília: Ministério da Educação, Cultura e Deporto, 2000, vol. 1.

REICHMANN, Carla L. Letras e letramentos. In: Letras e letramentos: escrita situada, identidade e trabalho docente no estágio supervisionado. - Campinas, SP: Mercado de Letras, 2015.

ROLDÃO, M. C. Função Docente: natureza e construção do conhecimento profissional. Revista Brasileira de Educação v. 12 n. 34 jan./abr. 2007.

SOUZA, A.L. S; Patrícia Santana; outros. Orientações a Ações Para a Educação das Relações Étnico-Raciais. Ensino Médio. In: BRASIL. Orientações a Ações Para a Educação das Relações Étnico-Raciais. Brasília: MEC/ SECAD, 2006.

TRAGTENBERG, Maurício. O papel social do professor. In: . Educação $e$ burocracia. São Paulo: Unesp, 2012.

2012. . Relações de poder na escola. In: . Educação e burocracia. São Paulo: Unesp,

VELLOSO, Mônica. Que cara tem o Brasil?: culturas e identidade nacional. Rio de Janeiro; Ediouro, 2000. 